\title{
Domino Metathesis of 3,6-dihydro-1,2-oxazine: Access to Isoxazolo[2,3-a]pyridin-7-ones
}

Géraldine Calvet, Nicolas Blanchard,*‡ and Cyrille Kouklovsky*

Laboratoire de Procédés et Substances Naturelles, Institut de Chimie Moléculaire et des matériaux d'ORSAY, ICMMO - UMR 8182-Bâtiment 410 Université Paris-Sud XI 15 rue Georges Clémenceau 91405 Orsay Cedex, France

nblanchard@icmo.u-psud.fr; cykouklo@icmo.u-psud.fr

1H, 13C NMR of compound 10

1H, 13C NMR of compound 14 3

1H, 13C NMR of compound 15 4

1H, 13C NMR of compound 16a 5

1H, 13C NMR of compound 16b 6

1H, 13C NMR of compound 16c 7

1H, 13C NMR of compound 16d 8

1H, 13C NMR of compound 16e 9

1H, 13C NMR of compound 18 10

1H, 13C NMR of compound 19 11

1H, 13C NMR of compound 20 12

1H, 13C NMR of compound 21 14 


\section{Compound 10}
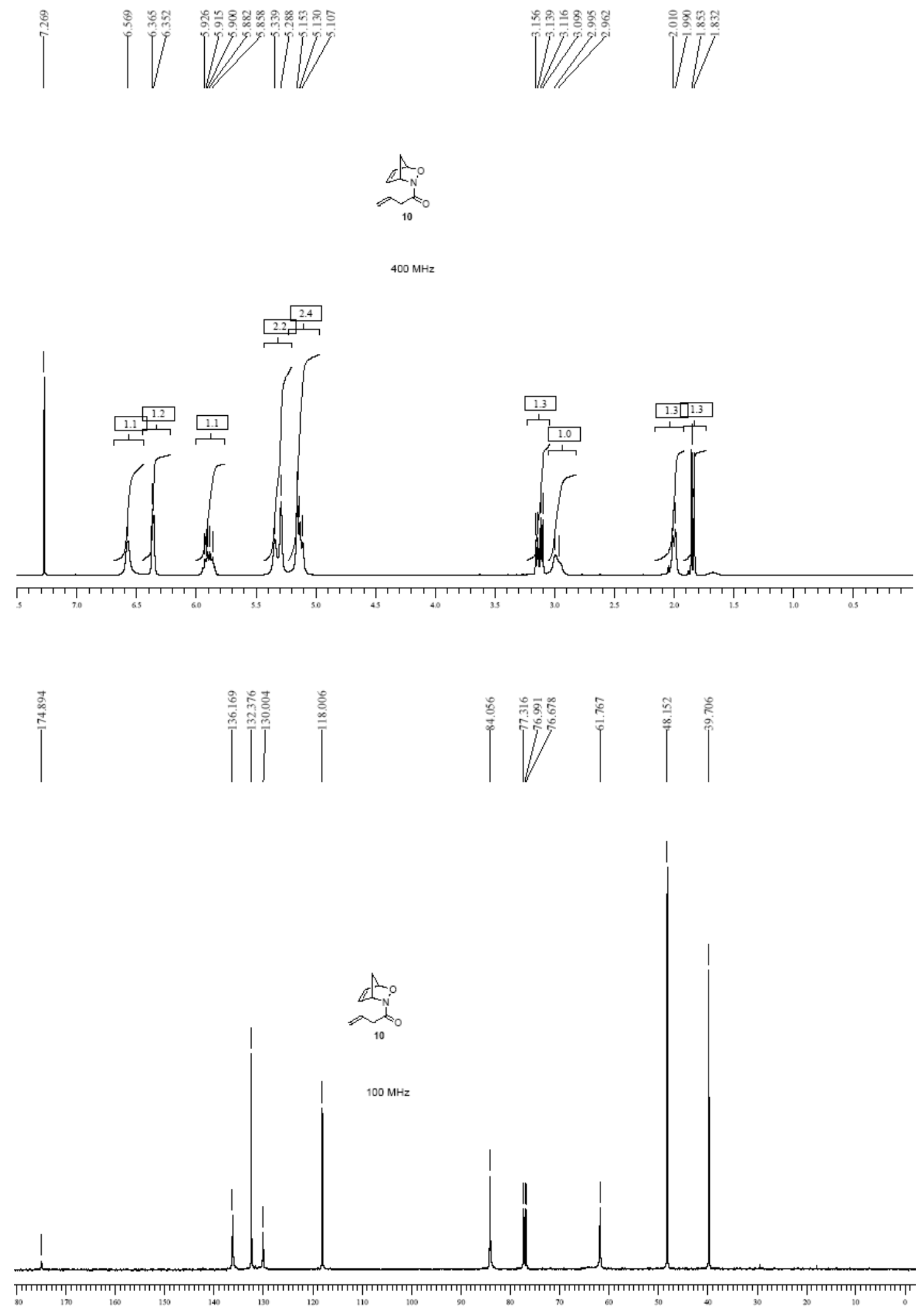


\section{Compound 14}

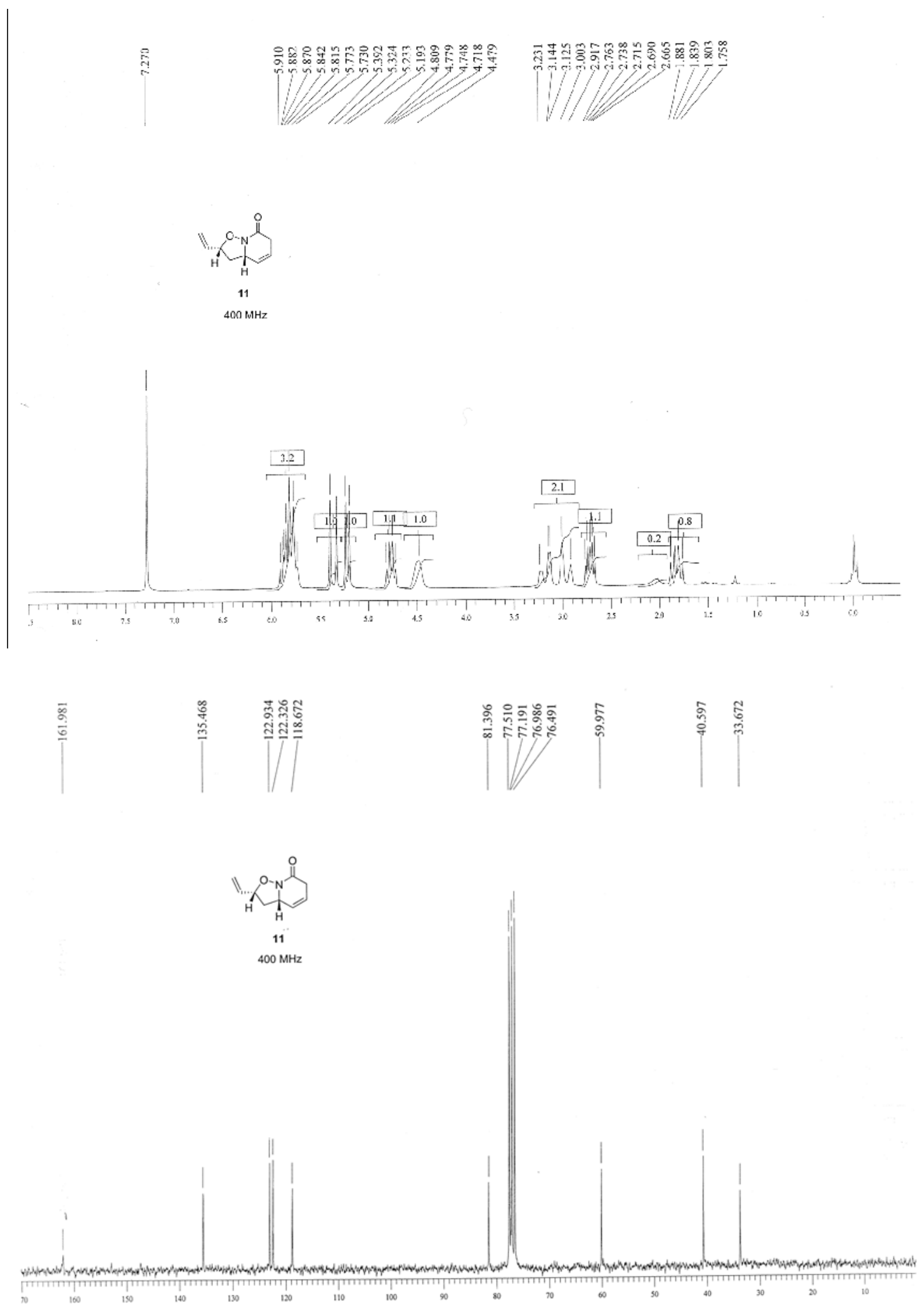




\section{Compound 15}
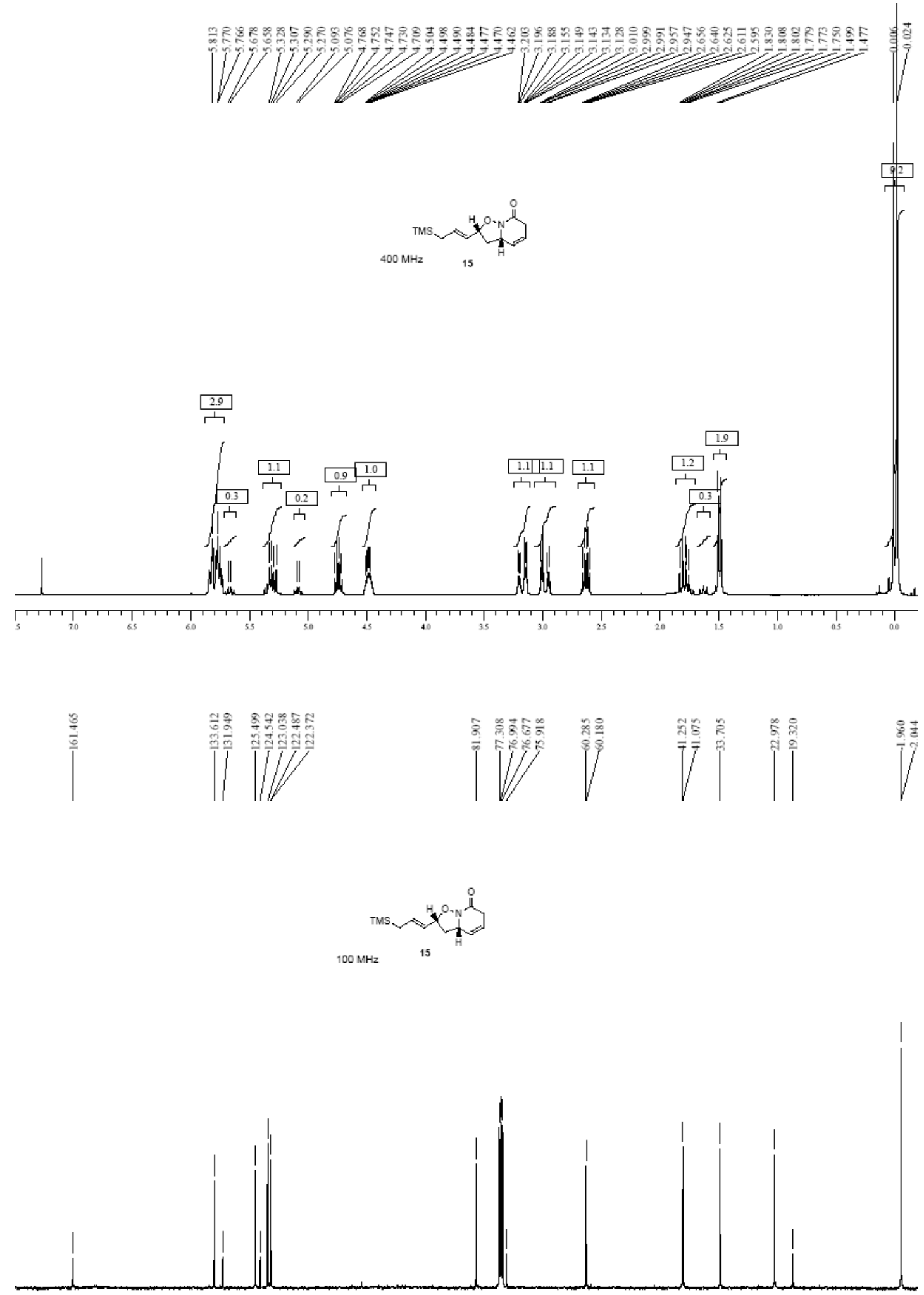

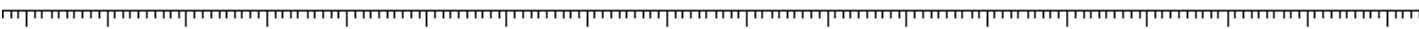




\section{Compound 16a}
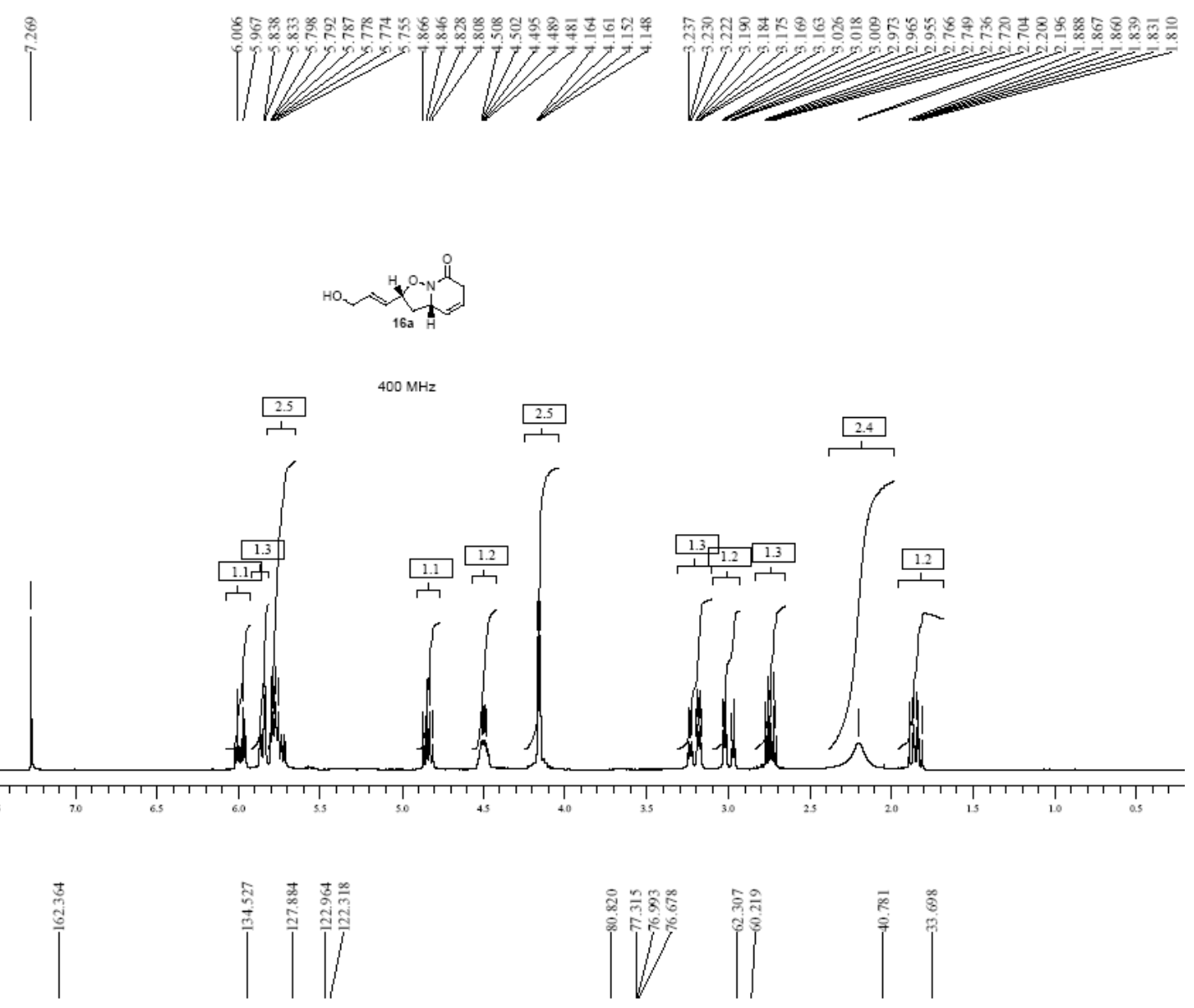

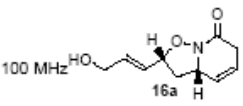

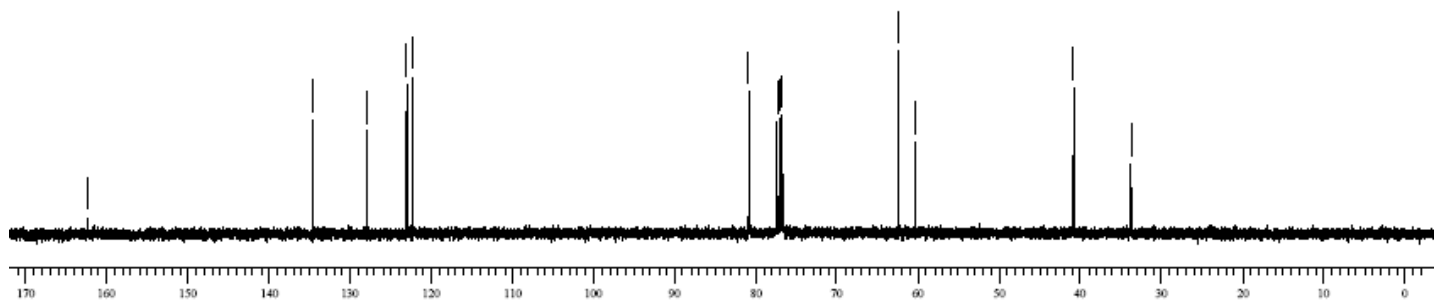




\section{Compound 16b}

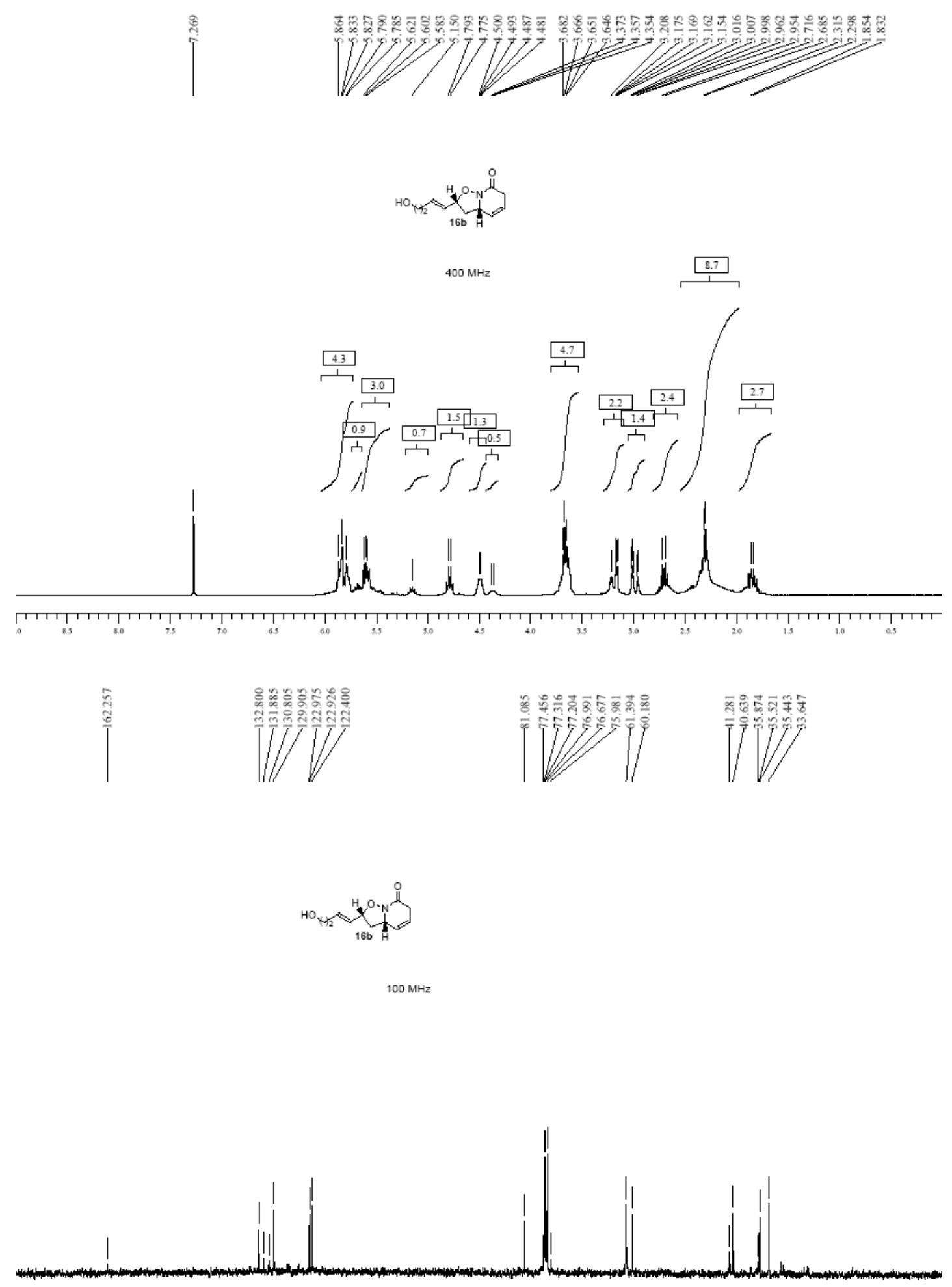

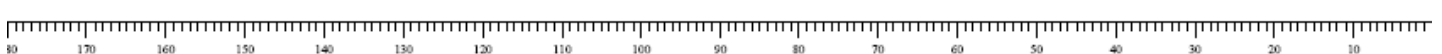




\section{Compound 16c}
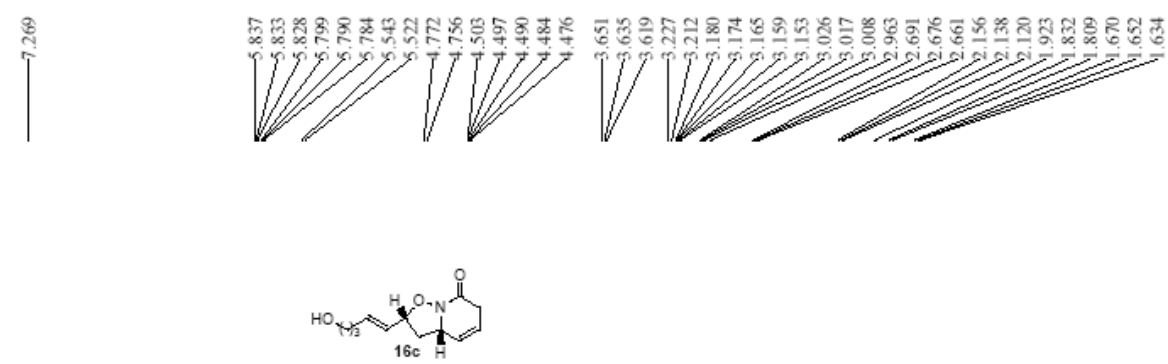

$400 \mathrm{MHz}$
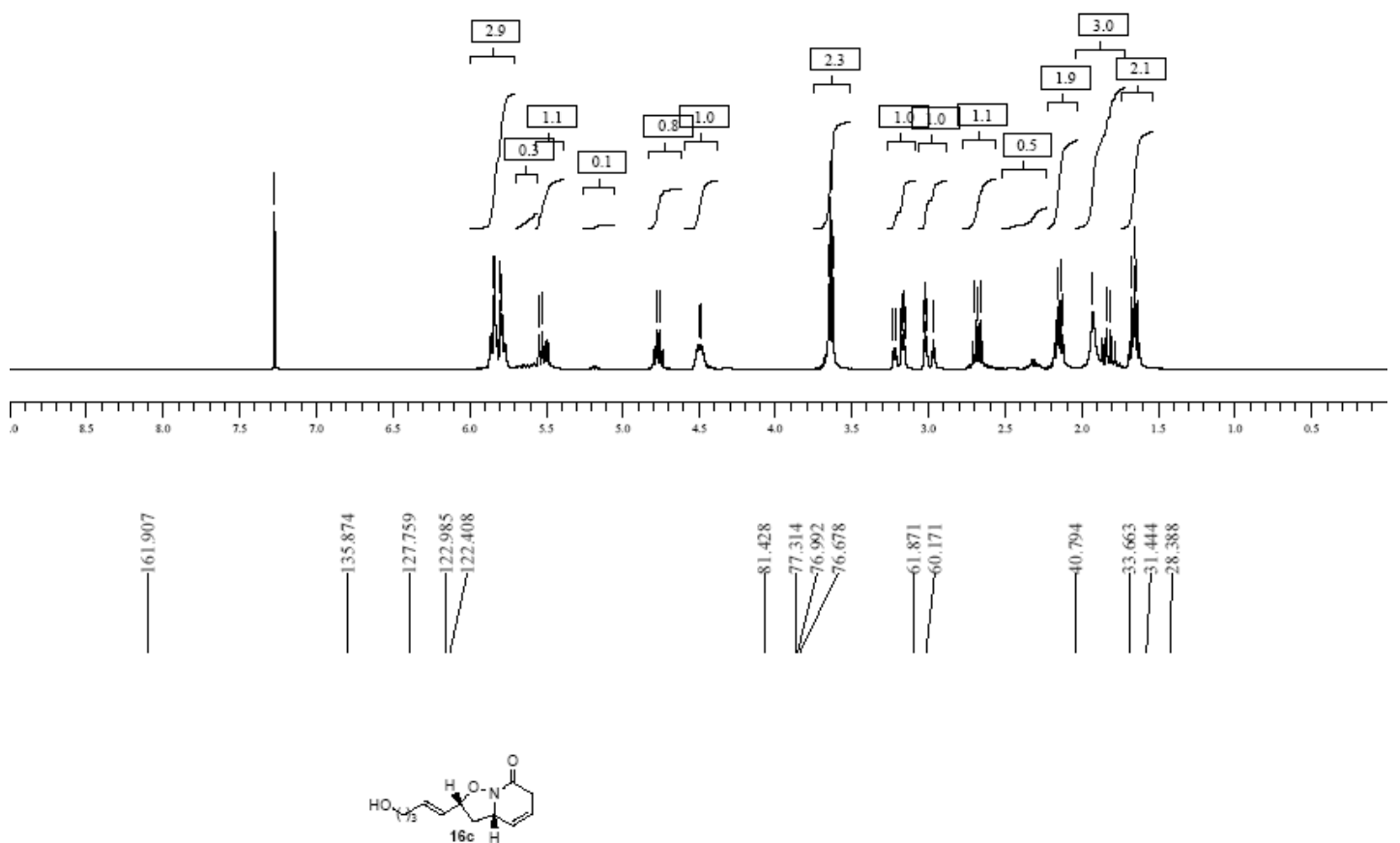

$100 \mathrm{MHz}$

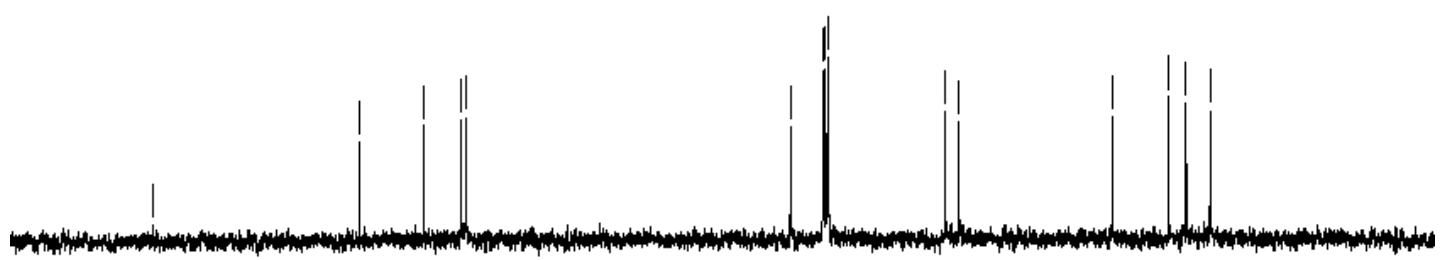

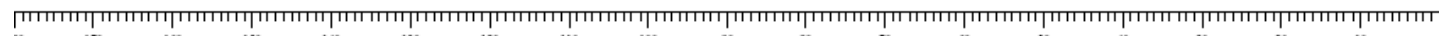




\section{Compound 16d}
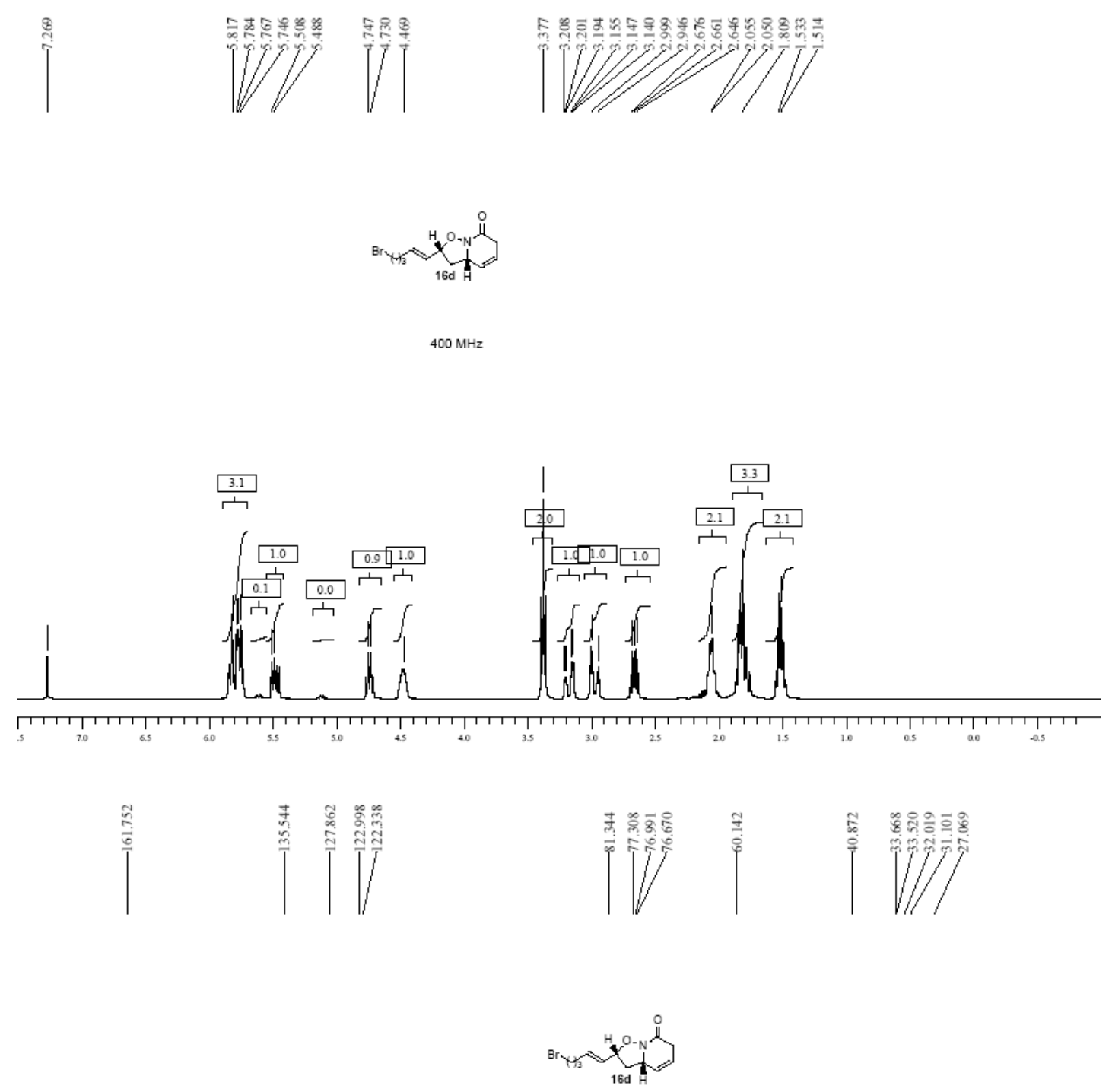

$100 \mathrm{MHz}$

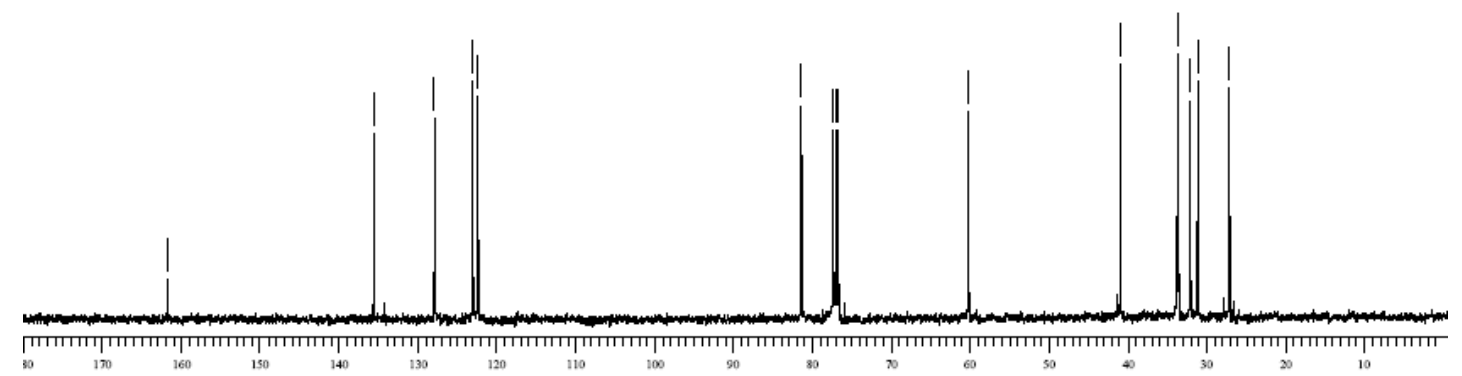




\section{Compound 16e}

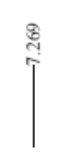
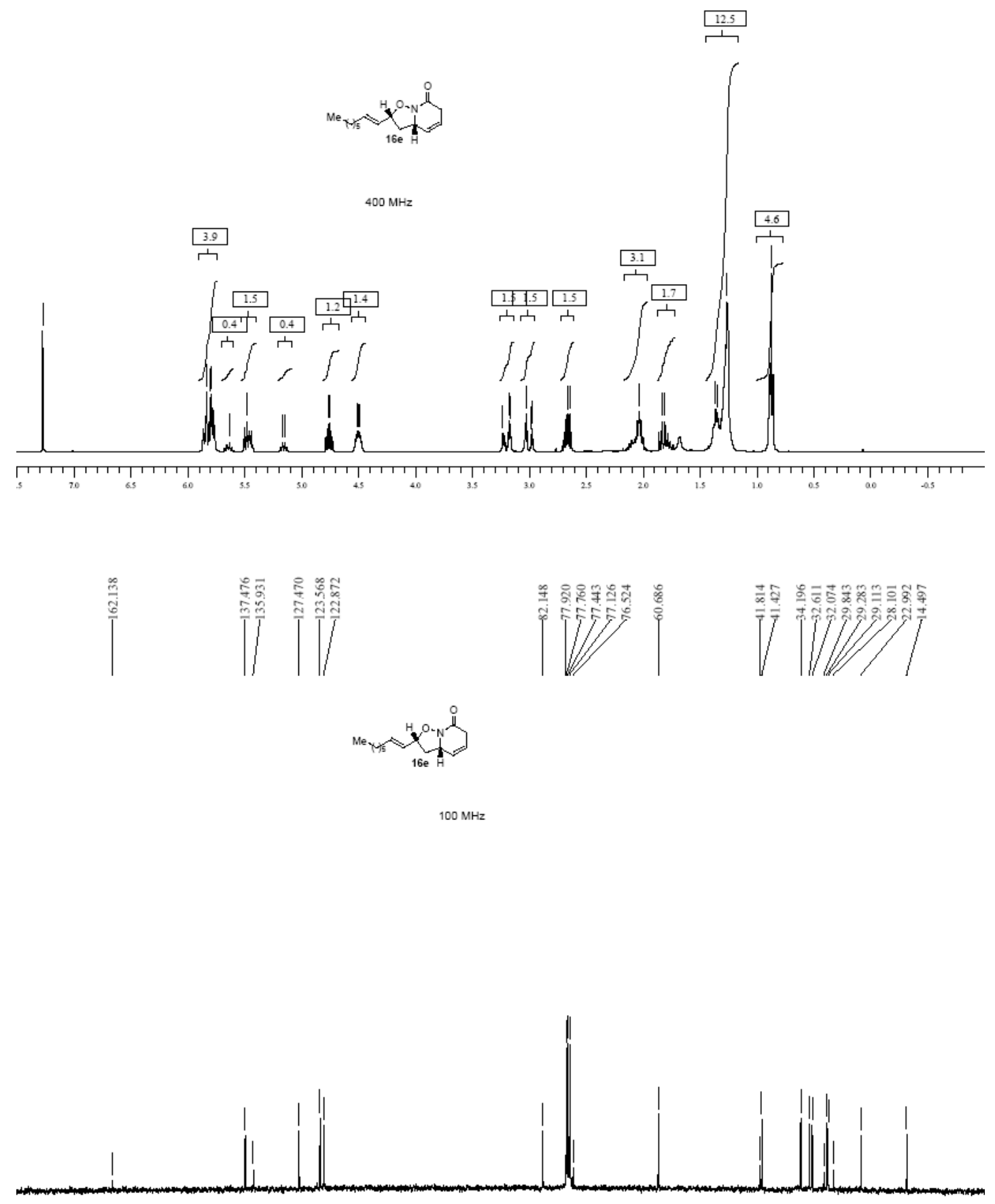

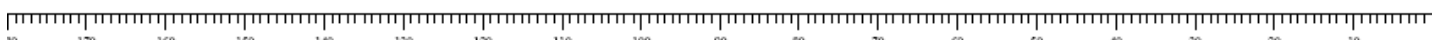




\section{Compound 18}
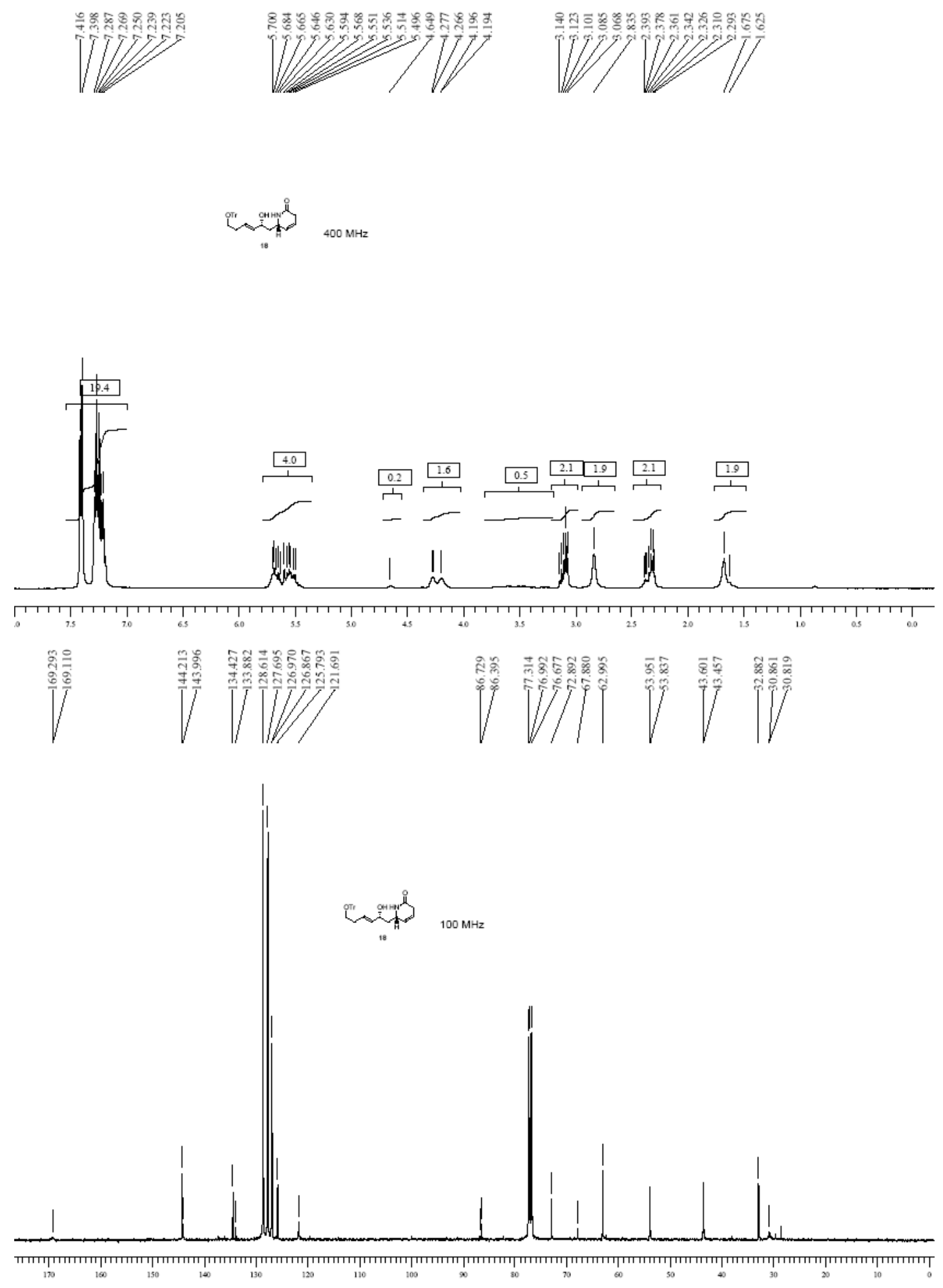


\section{Compound 19}

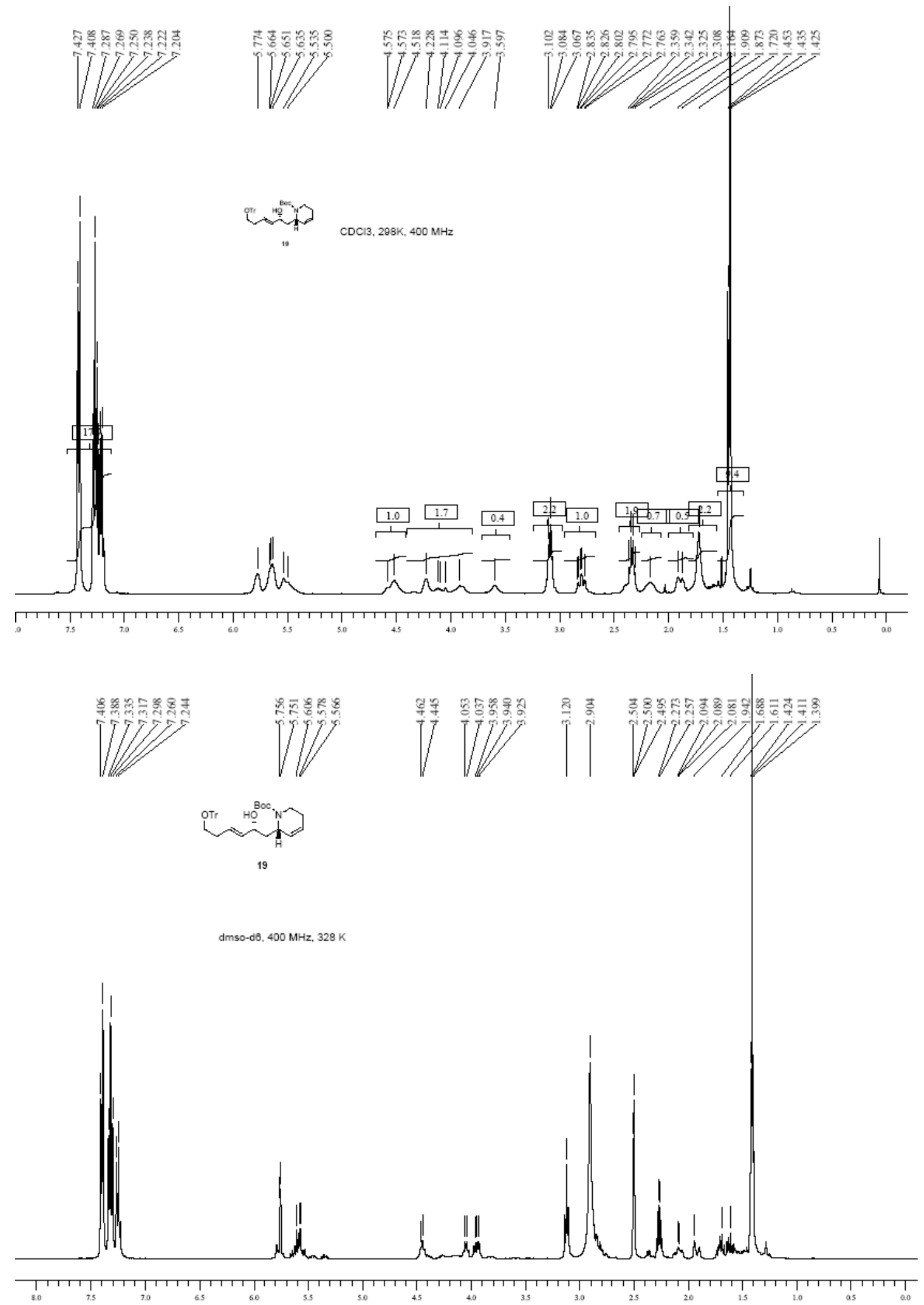



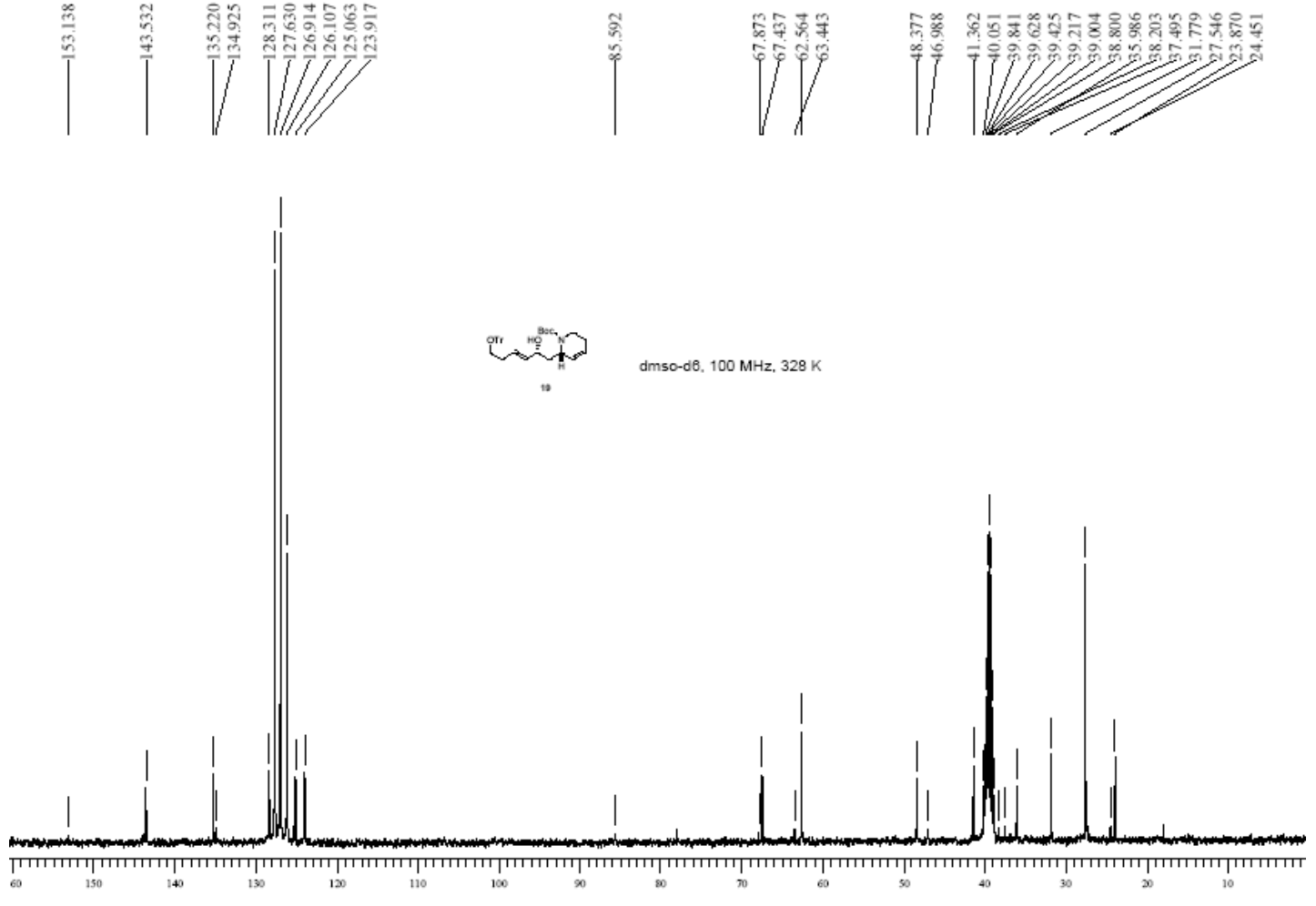

\section{Compound 20}
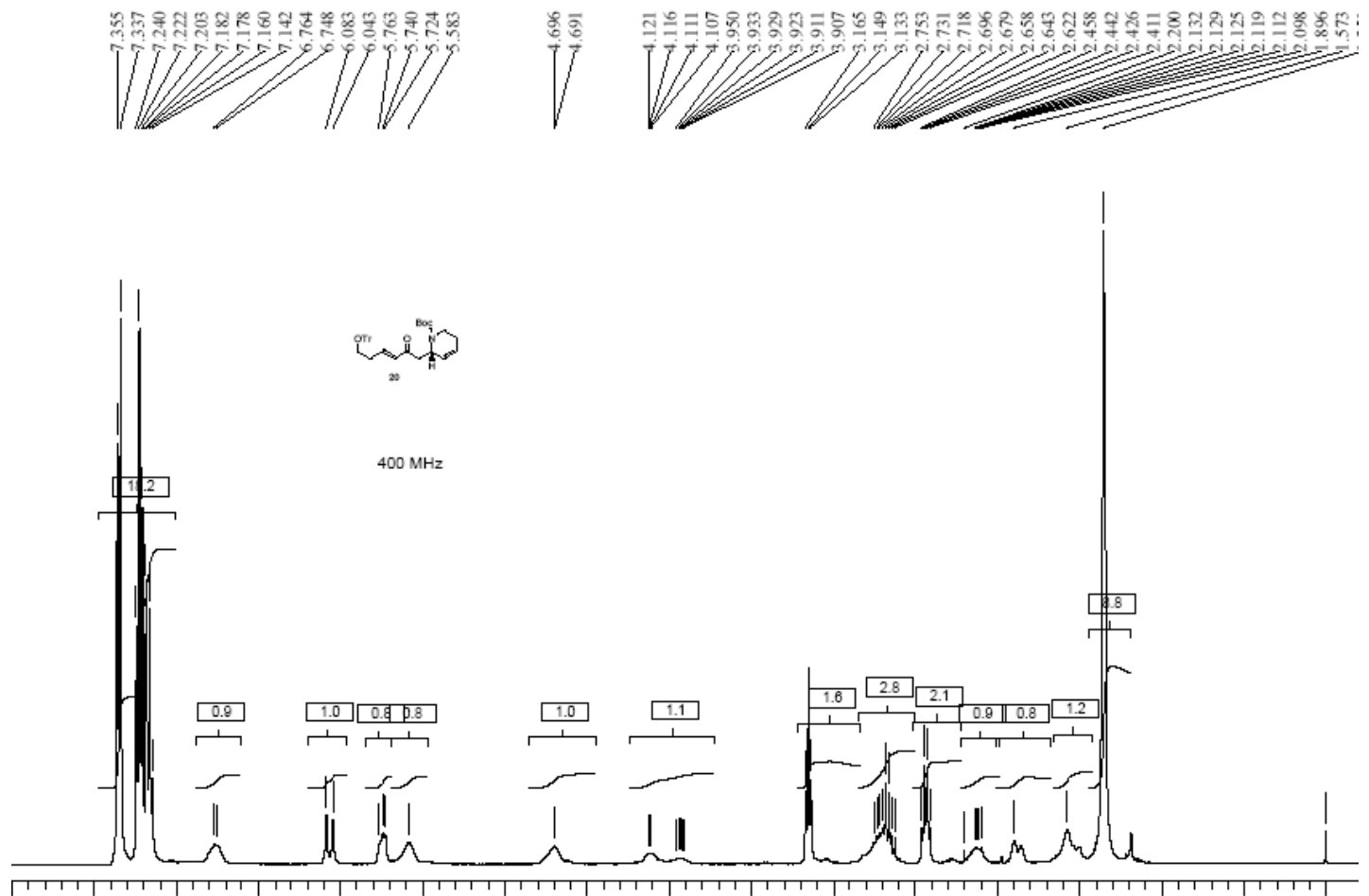

$$
{ }_{400 \mathrm{MHz}}^{\text {Mos }}
$$

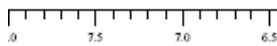




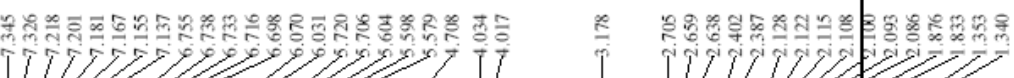

11
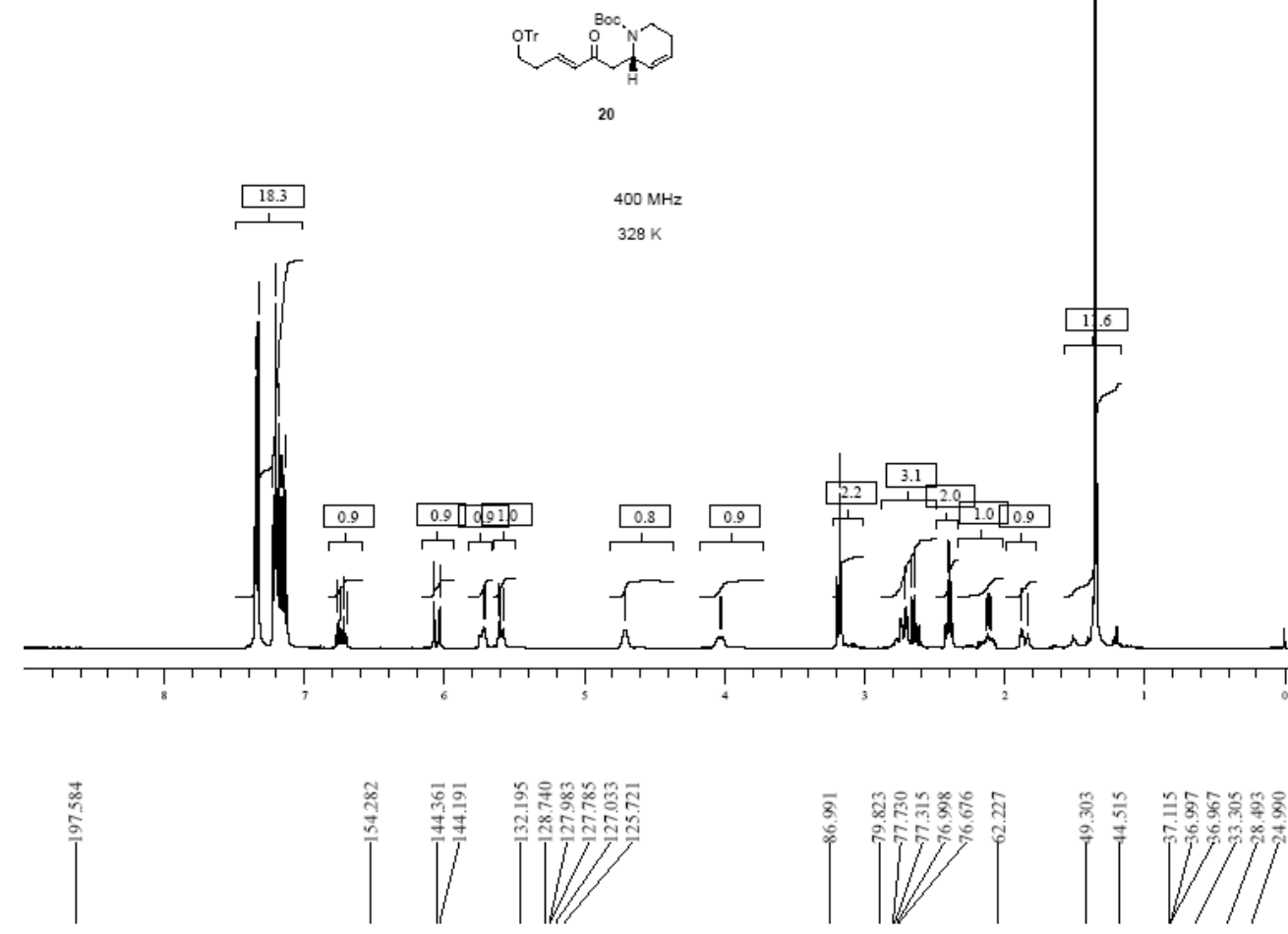

0

$28 \mathrm{~K}$

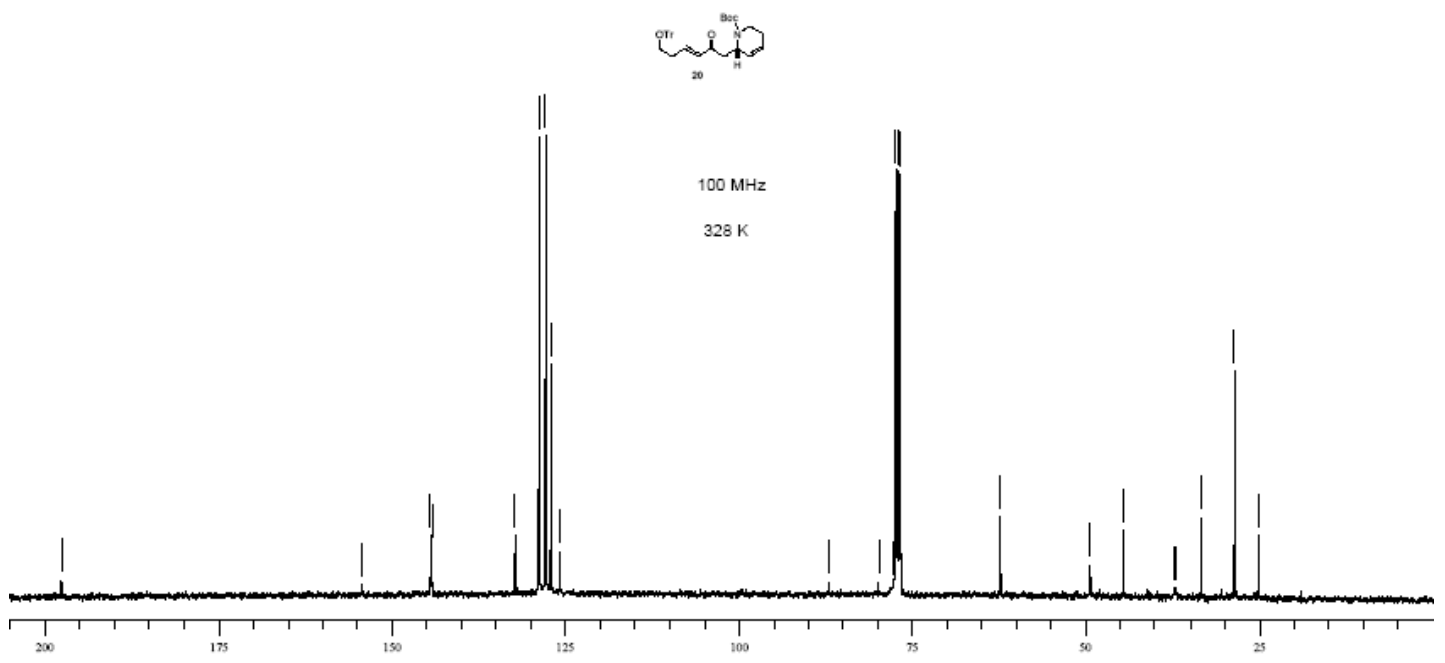




\section{Compound 21}

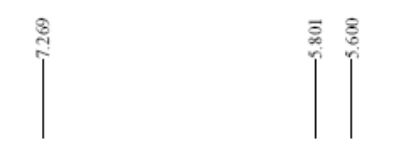

$\mathrm{C}_{\mathrm{N}}^{\mathrm{OH}}$

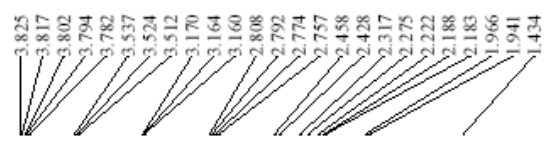

$400 \mathrm{MHz}$

\begin{tabular}{ll}
\hline 3.6 \\
\hline+1 \\
\hline
\end{tabular}
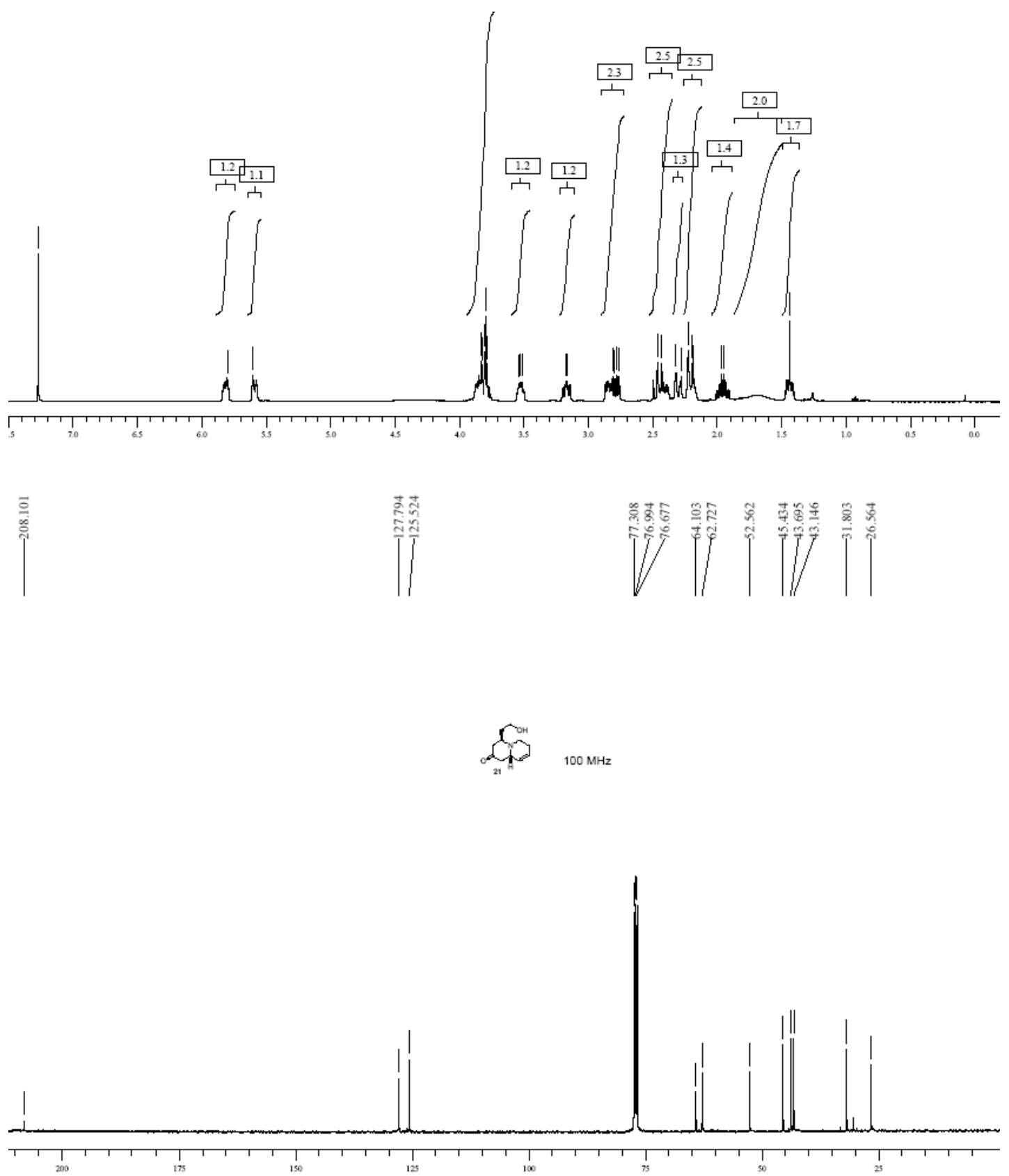